Arq. Bras. Med. Vet. Zootec., v.69, n.4, p.870-876, 2017

\title{
Efeito da suplementação parenteral extra de cobre e zinco sobre a resposta imunológica de vacas Nelore
}

\author{
[Effects of parenteral over-supplementation of cooper and zinc on \\ immune response of Nellore cows] \\ J.S. Silva ${ }^{1}$, M.A. Zanetti ${ }^{1}$, R.S.B. Carvalho ${ }^{1}$, S.N. Macedo ${ }^{1}$, R.F. Calviello ${ }^{1}$, \\ R.S.S. Santana ${ }^{2}$, R.S.N. Barreto ${ }^{3}$ \\ ${ }^{1}$ Faculdade de Zootecnia e Engenharia de Alimentos - Universidade de São Paulo (USP) - Pirassununga, SP \\ ${ }^{2}$ Instituto Federal de Educação Ciência e Tecnologia do Amazonas - (Ifam-CTB) - Tabatinga, AM \\ ${ }^{3}$ Faculdade de Medicina Veterinária e Zootecnia - Universidade de São Paulo (USP) - São Paulo, SP
}

\section{RESUMO}

O objetivo deste estudo foi avaliar o efeito da suplementação mineral injetável extra de cobre $(\mathrm{Cu})$ e zinco $(\mathrm{Zn})$ sobre a resposta imunológica de vacas Nelore no período pré-parto. Foram avaliadas 60 vacas prenhes, as quais foram divididas em dois tratamentos, por meio da distribuição aleatória em delineamento inteiramente ao acaso. Aos 75 dias antes do parto, as vacas do tratamento testemunha (T) receberam soro fisiológico como placebo e os animais suplementados (S) receberam mineral injetável via subcutânea $(75 \mathrm{mg}$ de cobre e $250 \mathrm{mg}$ de zinco, em dose única). Foram realizadas três coletas de sangue, duas antes da data prevista para o parto (75 e 10 dias) e uma 30 dias após o parto. Os teores de $\mathrm{Cu}$, Zn, ceruloplasmina, imunoglobulinas $\mathrm{G}(\operatorname{IgG})$ e $\mathrm{M}$ (IgM) foram analisados durante as três coletas. A atividade fagocitária foi avaliada aos 30 dias pós-parto. Os dados foram examinados mediante análise de variância, com o uso do pacote estatístico do SAS, e os dados individuais da atividade fagocitária pelo PROC GLM. Os dados de $\mathrm{Cu}, \mathrm{Zn}, \mathrm{IgG}$ e IgM foram analisados como medidas repetidas no tempo de coleta por meio do PROC MIXED, com o nível de significância de 5\%. Os teores de $\mathrm{Cu}, \mathrm{Zn}, \mathrm{IgM}$, IgG, ceruloplasmina e a atividade fagocitária das vacas não sofreram influência dos tratamentos $(\mathrm{P}>0,05)$. O fornecimento de $\mathrm{Cu}$ e $\mathrm{Zn}$ injetável, nas doses utilizadas, aos 75 dias antes do parto para vacas Nelore, em dietas suficientes, não alterou os teores de $\mathrm{Cu}, \mathrm{Zn}$, ceruloplasmina e a resposta imunológica até 30 dias após o parto.

Palavras-chave: atividade fagocitária, imunoglobulinas, minerais

\begin{abstract}
The aim of this study was to evaluate the effect of extra injectable mineral supplementation of copper (Cu) and zinc $(\mathrm{Zn})$ on the immune response of Nellore cows in pre-partum period. Sixty pregnant cows were randomly distributed in a completely randomized design in two treatments. In the control treatment (T), cows received saline as placebo, and supplemented treatment (S) received mineral injection (75mg copper and 250mg of zinc, single dose) subcutaneously, 75 days prior to parturition. Blood was sampled three times, two before the expected date of parturition (75 and 10 days) and another at 30 days postpartum. Analyses were performed for $\mathrm{Cu}, \mathrm{Zn}$, ceruloplasmin, immunoglobulin $\mathrm{G}(\mathrm{Ig} G)$ and $\mathrm{M}(\mathrm{IgM})$ in the three periods and the phagocytic activity in the last period (30 days postpartum). The experimental data were subjected to analysis of variance using the statistical package SAS, being that the individual data phagocytic activity were analyzed by PROC GLM, and the $\mathrm{Cu}, \mathrm{Zn}, \mathrm{IgG}$ and IgM were analyzed as repeated measures in the time, using the PROC MIXED, with the significance level of 5\%. The $\mathrm{Cu}, \mathrm{Zn}, \mathrm{IgM}, \mathrm{IgG}$, ceruloplasmin and the phagocytic activity of the cows were not affected by treatments $(P>0.05)$. The supply of injectable $\mathrm{Cu}$ and $\mathrm{Zn}$, at the doses used, 75 days before parturition to Nellore cows in sufficient diets, did not alter the serum contents of $\mathrm{Cu}, \mathrm{Zn}$, ceruloplasmin and the immune response up to 30 days after parturition.
\end{abstract}

Keywords: phagocytic activity, immunoglobulins, minerals

Recebido em 3 de agosto de 2016

Aceito em 10 de outubro de 2016

E-mail: janaina.silveira.silva@usp.br 


\section{INTRODUÇÃO}

Nos países subtropicais, a produção de vacas de corte tem as forrageiras como a principal fonte de alimento. Em diversas regiões, os níveis de $\mathrm{Cu}$ e $\mathrm{Zn}$ são deficientes nas pastagens, principalmente no Brasil (Wunsch et al., 2005; Nicodemo et al., 2008), portanto a suplementação com $\mathrm{Cu}$ e $\mathrm{Zn}$ em dieta de vacas de corte é necessária, principalmente no final da gestação, quando as exigências estão aumentadas (Meschy, 2010). O cobre (Cu) e o zinco (Zn) são considerados essenciais para $\mathrm{o}$ bom funcionamento do sistema imunológico. A deficiência de $\mathrm{Cu}$ pode prejudicar as células $\mathrm{T}$ e $\mathrm{B}$, os neutrófilos e os macrófagos, o que resulta em um decréscimo das células produtoras de anticorpos, diminuindo a resposta imune (McDowell, 1999). O zinco é fundamental para a resposta imune mediada por células, além de funcionar como agente antioxidante e antiinflamatório (Prasad, 2007).

O fornecimento de misturas minerais completas ad libitum é a prática de suplementação mais comum. No entanto, a variação no consumo individual é alta (Olson, 2007) e diversos fatores podem influenciar na absorção dos minerais, como a idade, a raça, o sexo, as condições ambientais, o $\mathrm{pH}$ intestinal, o estado fisiológico do animal e a presença de antagonistas na dieta (Underwood e Suttle, 2010). Mesmo recebendo níveis adequados de cobre na dieta, os animais podem apresentar sinais clínicos da deficiência (Marques et al., 2014), sendo importante, nesse caso, uma suplementação extra. O Brasil apresenta uma enorme disparidade nos métodos de suplementação mineral, pois alguns pecuaristas suplementam os animais de maneira irregular e descontínua, fornecem apenas cloreto de sódio, diluem o núcleo concentrado mineral de forma incorreta e ainda existe o problema da ingestão insuficiente dos animais devido a questões de acesso, localização, altura, espaçamento e cobertura dos cochos (Peixoto et al., 2005). A suplementação mineral por meio de injeções assegura que todos os animais recebam as quantidades necessárias, contorna problemas de interações indesejáveis na dieta e não necessita de absorção pelo trato gastrointestinal, que, no caso do cobre, é muito baixa (Mundell et al., 2012; Genther e Hansen, 2014). Dessa forma, o uso de injeções torna-se uma alternativa eficaz para a suplementação mineral e mais confiável para a garantia do status mineral adequado.

Alguns trabalhos demonstraram que o uso de um composto mineral injetável (TMI) contendo cobre $(\mathrm{Cu})$, manganês $(\mathrm{Mn})$, selênio $(\mathrm{Se})$ e zinco (Zn) melhorou o desempenho reprodutivo de bovinos de corte (Sales et al., 2011; Mundell et al., 2012), aumentou o teor de $\mathrm{Cu}$ no fígado (Daugherty et al., 2002; Pogge et al., 2012), aumentou a atividade da enzima superóxido dismutase (Machado et al., 2014), melhorou o desempenho de novilhas de corte (Richeson e Kegley, 2011) e aumentou a resposta imune humoral de bezerros de corte (Arthington e Havenga, 2012). No entanto, estudos avaliando a combinação apenas de cobre e zinco injetável e o seu efeito sobre a resposta imunológica de vacas de corte no período pré-parto são escassos. Além disso, o terço final da gestação é quando o feto apresenta seu desenvolvimento máximo, portanto as exigências são maiores, justificando a atenção especial e o fornecimento extra de minerais nesse período. Em virtude disso, o objetivo deste estudo foi avaliar o efeito da suplementação mineral injetável de cobre e zinco no período pré-parto de vacas Nelore sobre a resposta imunológica.

\section{MATERIAL E MÉTODOS}

Todos os procedimentos foram aprovados pelo Comitê de Ética em Pesquisa (CEP) da Faculdade de Zootecnia e Engenharia de Alimentos (FZEA/USP), certificado $\mathrm{n}^{\mathbf{0}}$ 13.1.2229.74.3.

O experimento foi realizado no setor de bovinocultura de corte da Prefeitura do Campus Administrativo da Universidade de São Paulo, em Pirassununga, SP (21 ${ }^{\circ} 59^{\prime}$ de latitude sul, $47^{\circ}$ $25^{\prime}$ de longitude oeste e altitude de $634 \mathrm{~m}$ ). Foram selecionadas 60 vacas da raça Nelore prenhes, com quatro a oito anos de idade, de segunda ou mais parições e escore de condição corporal (ECC) de 5,5 50,6 . O experimento foi desenvolvido no período que compreendeu de $75 \pm 9$ dias antes da data prevista para o parto até 30 dias após o parto. As vacas foram divididas aleatoriamente em dois tratamentos: testemunha (T), que recebeu soro fisiológico como placebo; e suplementado (S), que recebeu $75 \mathrm{mg}$ de $\mathrm{Zn}$ e $250 \mathrm{mg}$ de $\mathrm{Cu}$ via subcutânea, em dose única, aos $75 \pm 9$ dias antes do parto. O produto utilizado no 
tratamento suplementado continha como princípio ativo cobre metálico EDTA $(15,0 \mathrm{mg}$ de $\mathrm{Cu} / \mathrm{mL}$ ) e zinco metálico EDTA (50mg de $\mathrm{Zn} / \mathrm{mL}$ ).

Durante todo o período do experimento, as vacas receberam o mesmo manejo nutricional, permaneceram juntas em piquetes de braquiária (Brachiaria decumbens), de aproximadamente 19ha, recebendo mineral proteinado e água ad libitum. O proteinado foi ofertado para um consumo de $300 \mathrm{~g} / \mathrm{animal} / \mathrm{dia}$, que corresponde ao manejo tradicionalmente aplicado na unidade de produção. Esse suplemento era composto de 40\% de milho grão moído, $12,5 \%$ de ureia pecuária, $20 \%$ de farelo de algodão (38\% PB), $20 \%$ de cloreto de sódio e 7,5\% de núcleo mineral (nível de garantia por $\mathrm{kg}$ : cálcio $208 \mathrm{~g}$, cobalto $148 \mathrm{mg}$, cobre $2.664 \mathrm{mg}$, enxofre $64 \mathrm{~g}$, flúor (máx.) $1.600 \mathrm{mg}$, fósforo $160 \mathrm{~g}$, iodo $141 \mathrm{mg}$, manganês $2.220 \mathrm{mg}$, selênio $37 \mathrm{mg}$, zinco $7.992 \mathrm{mg}$, monensina sódica $4.000 \mathrm{mg}$; Minerthal 160 $\mathrm{MD}^{\circledR}$, Minerthal, Brasil). Mensalmente, foram realizadas amostragens do pasto consumido pelos animais, observando-se o hábito deles e a altura de pastejo para coleta de amostra semelhante (simulação de pastejo), por um único amostrador, para determinação dos minerais $\mathrm{Cu}$ e $\mathrm{Zn}$.

Foram realizadas três coletas de sangue, no período da manhã, por punção da jugular, com agulhas $25 \times 0,7 \mathrm{~mm}$ (BD Vacutainer $^{\circledR}$, PrecisionGlide, BD), utilizando-se tubos a vácuo de $10 \mathrm{~mL}$ sem anticoagulante (BD Vacutainer ${ }^{\circledR}$, tubo seco, BD). A primeira coleta foi realizada $75 \pm 9$ dias antes da data prevista para o parto, imediatamente antes de serem administradas a vacina de clostridiose e a injeção dos tratamentos. A segunda coleta foi realizada 10 dias antes do parto, e a última aos 30 dias pósparto. Imediatamente após as coletas, as amostras de sangue foram centrifugadas a 3.000rpm durante 15 minutos para a remoção do soro. A quantidade de $2,5 \mathrm{~mL}$ de soro foi encaminhada ao laboratório para a análise de $\operatorname{IgG}$ e $\operatorname{IgM}$, e a quantidade restante foi congelada a $-20^{\circ} \mathrm{C}$ para posteriores análises de $\mathrm{Cu}, \mathrm{Zn}$ e ceruloplasmina. As quantidades de $\mathrm{Cu}$ e $\mathrm{Zn}$ no soro, na pastagem e no suplemento mineral proteinado, foram determinadas no Laboratório de Minerais do Departamento de Zootecnia da FZEA-USP, segundo a metodologia descrita por Fick et al. (1979), por espectrometria de absorção atômica.
A atividade da ceruloplasmina no soro foi determinada pelo método descrito por Schosinsky et al. (1974), usando-se oDianisidine dihydrochloride como substrato, reagente que é convertido em um produto amarelo na presença de ceruloplasmina e oxigênio. Após adição de ácido sulfúrico, essa reação enzimática cessa, ocorrendo a formação de uma solução rosada estável, cuja absorbância foi lida a $540 \mathrm{~nm}$ em espectrofotômetro (Perkin Elmer® Lambda 35, Waltham, Massachusetts, USA). As análises de imunoglobulinas foram avaliadas por nefalometria, em laboratório comercial (Laboratório DAC - Diagnóstico de Análises Clínicas, Pirassununga, SP).

Para a análise da capacidade fagocítica dos neutrófilos aos 30 dias pós-parto, o sangue total foi processado e o kit pHrodo ${ }^{\mathrm{TM}}$ E. coli BioParticles ${ }^{\circledR}$ Phagocytosis (Invitrogen, Eugene, Oregon, USA) foi utilizado de acordo com as orientações do fabricante. As amostras obtidas foram analisadas no Núcleo de Proteômica da Faculdade de Ciências Farmacêuticas da Unesp de Araraquara, por meio da citometria de fluxo (BD FACS Canto I, BD Biosciences, San Jose, CA, USA). As análises dos dados obtidos foram realizadas mediante o uso do software FCS Express versão 4 (De Novo Software).

Foi utilizado delineamento inteiramente ao acaso, com dois tratamentos. Os dados do experimento foram submetidos à análise de variância, por meio do pacote estatístico do SAS (SAS, Institute Inc, Cary, USA). Os dados individuais da atividade fagocitária foram avaliados pelo PROC GLM, e os dados de $\mathrm{Cu}$, $\mathrm{Zn}$, IgG e IgM foram analisados como medidas repetidas no tempo de coleta, mediante o uso do PROC MIXED, com o nível de significância de $5 \%$. Os dados foram examinados em relação à presença de outliers e à normalidade dos resíduos (teste de Shapiro-Wilk).

\section{RESULTADOS E DISCUSSÃO}

As concentrações de cobre e zinco no soro das vacas aos 75 e 10 dias antes do parto e aos 30 dias pós-parto não diferiram entre os tratamentos $(\mathrm{P}>0,05)$. Não houve interação tratamento versus tempo $(\mathrm{P}>0,05)$, entretanto foi observado efeito entre tempos de coletas $(\mathrm{P}<0,0001)$ (Fig. 1). 


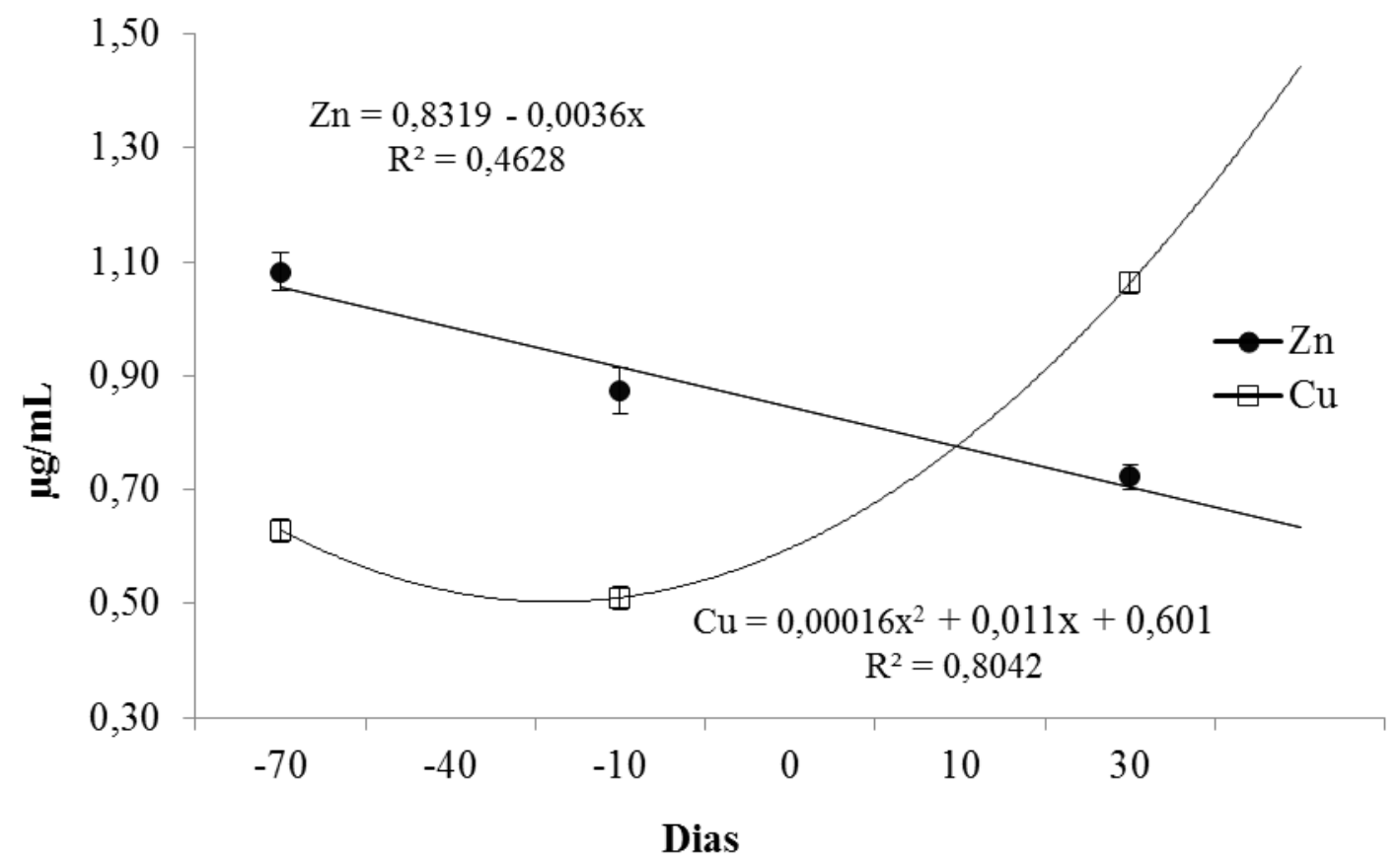

Figura 1. Curvas das concentrações médias de cobre $(\mathrm{Cu})$ e zinco $(\mathrm{Zn})$, em $\mu \mathrm{g} / \mathrm{mL}$, no soro de vacas Nelore dos 75 dias pré-parto aos 30 dias pós-parto, e respectivos erros- padrão.

Os teores séricos médios de $\mathrm{Cu}(0,8367$ e 0,8496 $\mu \mathrm{g} / \mathrm{mL})$ e $\mathrm{Zn}(0,8618$ e $0,8236 \mu \mathrm{g} / \mathrm{mL})$ foram semelhantes entre os tratamentos testemunha e suplementado, respectivamente. Esses valores estão acima dos valores marginais relatados por Underwood e Suttle (2010), que consideram indicativos de deficiência níveis de $\mathrm{Cu}$ e $\mathrm{Zn}$ abaixo de 0,6 $\mu \mathrm{g} / \mathrm{mL}$. Daugherty et al. (2002) também não observaram alterações nos valores de $\mathrm{Cu}$ e $\mathrm{Zn}$ plasmático em vacas de corte recebendo um composto mineral injetável de cobre, zinco, selênio, manganês e vitamina E no pré-parto e no pré-acasalamento.

Apenas valores séricos de cobre abaixo de $0,5 \mu \mathrm{g} / \mathrm{mL}$ são acompanhados de baixos valores hepáticos, o que resultaria em diferença significativa nos níveis plasmáticos de cobre (Claypool et al., 1975). Como no presente experimento o teor médio de $\mathrm{Cu}$ sérico $(0,84 \mu \mathrm{g} / \mathrm{mlL})$ foi superior a $0,5 \mu \mathrm{g} / \mathrm{mL}$, as reservas hepáticas foram suficientes para manter a concentração adequada de $\mathrm{Cu}$ no soro das vacas.

A concentração de $\mathrm{Cu}$ sérico apresentou um efeito quadrático, resultado semelhante ao descrito por Wang et al. (2014), que também verificaram menores teores de $\mathrm{Cu}$ na semana anterior ao parto e aumento gradual a partir da data do parto até a quarta semana pós-parto. No presente estudo, a concentração de $\mathrm{Zn}$ diminuiu linearmente no período que compreende os 75 dias antes do parto até os 30 dias pós-parto, concordando também com os resultados de Wang et al. (2014). A queda tanto do cobre quanto do zinco, mesmo com as vacas recebendo os níveis recomendados pelo Nutrient... (1996), indica que seria necessário um nível ainda maior desses minerais na ração nessa fase. Como o maior desenvolvimento do feto ocorre no final da gestação, a transferência desses minerais ao feto via placenta é a principal responsável pela queda sérica.

A avaliação da atividade da ceruloplasmina é interessante por ser um indicador indireto da concentração sérica de cobre (Borges et al., 2005). No presente estudo, a atividade da ceruloplasmina não diferiu entre os tratamentos testemunha $(7,93 \mathrm{U} / 1)$ e suplementado $(7,78 \mathrm{U} / 1)$ e não houve interação tratamento versus tempo $(\mathrm{P}>0,05)$. Houve diferença apenas entre os períodos avaliados $(\mathrm{P}<0,0001)$, sendo que, assim como o cobre sérico, a atividade da ceruloplasmina diminuiu aos 10 dias pré-parto. A 
falta de efeito do tratamento na ceruloplasmina deveu-se possivelmente ao fato de os níveis séricos de cobre estarem normais.

Os teores médios de cobre e zinco nas pastagens foram de 3,96 e $13,63 \mathrm{mg} / \mathrm{kg}$ de MS, respectivamente, valores que estão muito abaixo das exigências propostas pelo NRC (Nutrient..., 1996), de $10 \mathrm{mg}$ de $\mathrm{Cu} / \mathrm{kg}$ de MS e de $30 \mathrm{mg}$ de $\mathrm{Zn} / \mathrm{kg}$ de MS. Entretanto, além das pastagens, as vacas receberam um suplemento mineral proteinado com $205 \mathrm{mg}$ de $\mathrm{Cu} / \mathrm{kg}$ de $\mathrm{MS}$ e $608 \mathrm{mg}$ de $\mathrm{Zn} / \mathrm{kg}$ de MS. Ao se considerar uma ingestão média de $9,9 \mathrm{~kg}$ de MS e o consumo médio observado de $290 \mathrm{~g} /$ dia do suplemento, verificase que as vacas ingeriram aproximadamente $98,77 \mathrm{mg}$ de $\mathrm{Cu}$ (praticamente o recomendado, $99 \mathrm{mg}$ de $\mathrm{Cu})$ e $311,35 \mathrm{mg}$ de $\mathrm{Zn}$ (4,8\% superior ao recomendado, $297 \mathrm{mg}$ de $\mathrm{Zn}$ ). Como pode ser visto, pelos cálculos acima, as vacas receberam praticamente as quantidades recomendadas de cobre e de zinco com a suplementação oral e, mesmo recebendo suplementação injetável extra aos 75 dias antes da parição, ocorreu redução dos níveis de $\mathrm{Cu}$ e $\mathrm{Zn}$ no soro das vacas próximo à data do parto. Uma das formas para evitar a queda nos níveis séricos de $\mathrm{Cu}$ e $\mathrm{Zn}$ seria repetir a aplicação do mineral mais próximo ao parto.

As concentrações de imunoglobulinas $\mathrm{G}$ e $\mathrm{M}$ não sofreram efeito dos tratamentos e não houve interação tratamento versus tempo $(\mathrm{P}>0,05)$. Entretanto, ocorreram diferenças nas concentrações de imunoglobulinas $\mathrm{G}$ e $\mathrm{M}$ entre os períodos avaliados $(\mathrm{P}<0,0001)$ (Fig. 2).

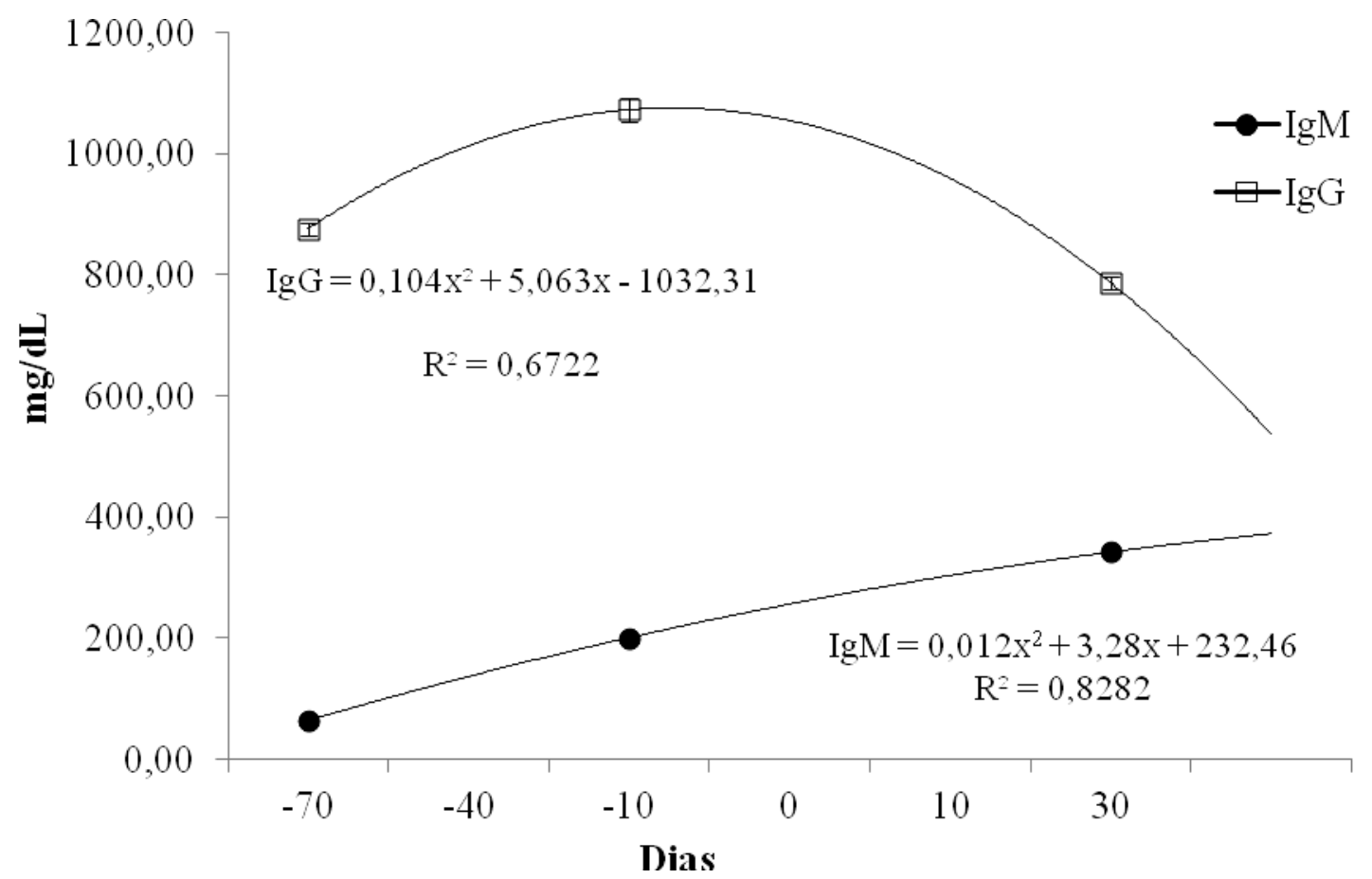

Figura 2. Curvas das concentrações médias de imunoglobulinas M (IgM) e G (IgG), em mg/dL, no soro de vacas Nelore, ao longo dos períodos do estudo, e respectivos erros- padrão.

As concentrações médias de $\operatorname{IgG}$ e $\operatorname{IgM}$ apresentaram um comportamento quadrático. Após receberem vacina contra clostridiose (aos 75 dias antes do parto), as concentrações de IgG e IgM aumentaram até o período de 10 dias antes do parto, como previsto, devido à exposição ao antígeno.
Novilhas vacinadas contra Brucella abortus e com deficiência de $\mathrm{Cu}$ induzida pela suplementação com Mo e S apresentaram menor concentração de IgG no soro (Cerone et al., 1995). Gengelbach e Spears (1998) também relataram menores concentrações de IgG e IgM em animais não suplementados com cobre ou 
com deficiência de $\mathrm{Cu}$ induzida. Entretanto, no presente experimento, as vacas receberam quantidades adequadas de cobre e zinco na dieta, o que explica a falta de resultado na resposta imunológica, que é o primeiro efeito a surgir com a deficiência desses minerais.

$\mathrm{O} \mathrm{Cu}$ e o $\mathrm{Zn}$ são minerais fundamentais na modulação do sistema imune. Dang et al. (2013) avaliaram a atividade fagocítica de neutrófilos com o uso do nitroazul tetrazolium (NBT) e leitura em espectrofotômetro. Esses autores relataram que vacas Sahiwal que receberam suplementação com $\mathrm{Cu}$ e $\mathrm{Zn}$ apresentaram maior atividade fagocítica de neutrófilos aos 30 dias antes e aos 45 dias pós-parto, possivelmente porque os animais estavam deficientes. Nesse experimento, a atividade fagocitária foi avaliada por citometria de fluxo, um método emergente e muito mais sensível que o NBT. Mesmo assim, o resultado da atividade fagocitária aos 30 dias pós-parto não foi diferente $(\mathrm{P}>0,05)$ entre os tratamentos testemunha e suplementado $(24,57 \%$ e $23,96 \%$, respectivamente), pois os animais ingeriram níveis adequados de $\mathrm{Cu}$ e $\mathrm{Zn}$.

\section{CONCLUSÕES}

A suplementação parenteral, aos 75 dias antes do parto, com $75 \mathrm{mg}$ de cobre e $250 \mathrm{mg}$ de zinco para vacas Nelore recebendo teores adequados desses minerais na dieta, não alterou o cobre e o zinco séricos, atividade da ceruloplasmina, bem como a resposta imunológica até 30 dias após o parto. A suplementação recomendada pelo NRC (Nutrient..., 1996) mais a injetável não foi suficiente para evitar a queda sérica no zinco e no cobre em vacas Nelore próximo ao parto, indicando que deve haver uma suplementação ainda maior nessa fase.

\section{AGRADECIMENTOS}

À Fundação de Amparo à Pesquisa do Estado de São Paulo (Fapesp).

\section{REFERÊNCIAS}

ARTHINGTON, J.D.; HAVENGA, L.J. Effect of injectable trace minerals on the humoral immune response to multivalent vaccine administration in beef calves. J. Anim. Sci., v.90, p.1966-1971, 2012.
BORGES, A.S.; AMORIM, R.M.; KUCHEMBUCK, M.R.G. et al. Correlação entre a atividade sérica da ceruloplasmina e os teores sérico e hepático de cobre em novilhas Nelore. Arq. Bras. Med. Vet. Zootec., v.57, p.150-155, 2005.

CERONE, S.I.; SANSINANEA, A.S.; AUZA, N.J. Copper deficiency alters the immune response of bovine. Nutr. Res., v.15, p.13331341, 1995.

CLAYPOOL, D.W.; ADAMS, F.W.; PENDELL, H.W. Relationship between the level of copper in the blood plasma and the liver of cattle. J. Anim. Sci., v.41, p.911-914, 1975.

DANG, A.K.; PRASAD, S.; DE, K. et al. Effect of supplementation of vitamin $\mathrm{E}$, copper and zinc on the in vitro phagocytic activity and lymphocyte proliferation index of peripartum Sahiwal (Bos indicus) cows. J. Anim. Physiol. Anim. Nutr., v.97, p.315-321, 2013.

DAUGHERTY, S.R.; CARSTENS, G.E.; HERD, D.B. et al. Effects of prenatal and prebreeding trace mineral/vitamin $E$ injections on calf health and reproductive performance of beef cows. Texas: College Station, 2002. p.3943.

FICK, K.R.; MCDOWELL, L.R.; MILES, P.H. et al. Methods of mineral analysis for plant and animals tissues. 2.ed. Gainesville: Dept. Anim. Sci., 1979. 90p.

GENGELBACH, G.P.; SPEARS, J.W. Effects of dietary copper and molybdenum on copper status, cytokine production, and humoral immune response of calves. J. Dairy Sci., v.81, p.3286-3292, 1998.

GENTHER, O.N.; HANSEN, S.L. A multielement trace mineral injection improves liver copper and selenium concentrations and manganese superoxide dismutase activity in beef steers. J. Anim. Sci., v.92, p.695-704. 2014.

MACHADO, V.S.; OIKONOMOU. G.; LIMA, S.F. et al. The effect of injectable trace minerals (selenium, copper, zinc, and manganese) on peripheral blood leukocyte activity and serum superoxide dismutase activity of lactating Holstein cows. Vet. J., v.200, p.299-304, 2014. 
MARQUES, A.P.L.; BOTTEON, R.C.C.M.; AMORIN, E.B. et al. Composição mineral das pastagens e deficiências minerais dos bovinos em algumas propriedades da região do Médio Paraína, RJ, Brasil. Rev. Bras. Med. Vet., v.36, p.71-78, 2014.

McDOWELL, L.R. Minerais para ruminantes sob pastejo em regiões tropicais, enfatizando o Brasil. 3.ed. Florida: University of Florida, 1999. $92 \mathrm{p}$.

MESCHY, F. Nutrition minérale des ruminants. Versailles: Éditions Quae, 2010. 208p.

MUNDELL, L.R.; JAEGER, J.R.; WAGGONER, J.W. et al. Effects of prepartum and postpartum bolus injections of trace minerals on performance of beef cows and calves grazing native range. Prof. Anim. Sci., v.28, p.82-88, 2012.

NICODEMO, M.L.F.; SERENO, J.R.B.; AMARAL, T.B. Minerais na eficiência reprodutiva de bovinos. São Carlos: EMBRAPA, 2008. 69p. (Documento 80).

NUTRIENT requirements of beef cattle. 7.ed. Washington: National Academy Press, 1996. 242p.

OLSON, K.C. Management of mineral supplementation programs for cow-calf operations. Vet. Clin. N. Am. Food Anim. Pract., v.23, p.69-90, 2007.

PEIXOTO, P.V.; MALAFAIA, P.; BARBOSA, J.D. et al. Princípios de suplementação mineral em ruminantes. Pesqui. Vet. Bras., v.25, p.195200, 2005.
POGGE, D.J., RICHTER, E.L.; DREWNOSKI, M.E. et al. Mineral concentrations of plasma and liver after injection with a trace mineral complex differ among Angus and Simmental cattle. J. Anim. Sci., v.90, p.2692-2698, 2012.

PRASAD, A.S. Zinc: mechanisms of host defense. J. Nutr., v.137, p.1345-1349, 2007.

RICHESON J.T., KEGLEY E.B. Effect of supplemental trace minerals from injection on health and performance of highly stressed, newly received beef heifers. Prof. Anim. Sci., v.27, p.461-466, 2011.

SALES, J.N.S.; PEREIRA, R.V.V.; BICALHO, R.C. et al. Effect of injectable copper, selenium, zinc and manganese on the pregnancy rate of crossbred heifers (Bos indicus $\times$ Bos taurus) synchronized for timed embryo transfer. Livest. Sci., v.142, p.59-62, 2011.

SCHOSINSKY， K.H.; LEHMANN， H.P.; BEELER, M.F. Measurement of cerulopalsmin from its oxidase activity in serum by use of oDianisidine Dihydrochloride. Clin. Chem., v.20, p.1556-1563, 1974.

UNDERWOOD, E.J.; SUTTLE, N.F. The mineral nutrition of livestock. 4.ed. New York: CAB International, 2010. 587p.

WANG, J.; ZHU, X.; WANG, Z. et al. Changes in serum copper and zinc levels in peripartum healthy and subclinically hypocalcemic dairy cows. Biol. Trace Elem. Res., v.159, p.135-139, 2014.

WUNSCH, C.; BARCELLOS, J.O.J.; PRATES, E.R. et al. Microminerais para bovinos de corte nas pastagens nativas dos Campos de Cima da Serra, RS, Brasil. Ciênc. Rural, v.35, p.903-908, 2005. 